\section{Systematic Changes in China}

\section{Qiang Zha ANd Chuany Wang}

Qiang Zha is an associate professor at the Faculty of Education, York University, Toronto, Canada. E-mail: qzha@edu.yorku.ca. Chuanyi Wang is a postdoctoral fellow at the Institute of Education, Tsinghua University, Beijing, China.

$\mathrm{C}$ hinese higher education struck the world with its amazing pace of expansion, since the late I990s. In the meantime, the Chinese system has become a steep hierarchy, which invites enormous concerns about whether higher education could still facilitate social mobility. Behind the scene, it is no secret that over 30 percent of the graduates from low echelon institutions are now having difficulties finding jobs upon graduation, while the prestigious elite universities are accused of nurturing the "refined egoist" among their students. In the postexpansion era, the Chinese system clearly needs to address issues pertaining to widening the path of social mobility (perceptually and practically) and increasing the relevance of participating in higher education. Changes are indeed occurring in Chinese higher education.

\section{Changes Occurring in the Chinese System}

At the top of the hierarchy, there appears to be a paradoxical move toward "recentralization." Chinese higher education clearly went through a process of decentralization in the I990s, whereby around 250 universities that used to be administered by the central ministries were now put under the jurisdiction of the provincial governments. In the meantime, the local higher education sector grew quickly, dominating China's higher education expansion since the late I990s. Some 500 new universities emerged, from amalgamation and upgrading of local colleges, while even more higher vocational colleges and private institutions came into being. Consequently, the national universities now represent a much smaller share of the Chinese system-6.6 percent in terms of proportion of all institutions and 8.7 percent of entire enrollment in 2010 (down from $32.8 \%$ and $43.9 \%$ in 1989 )-while the local sector now makes up the absolute bulk of the system, accounting for 93.4 percent and 9I.2 percent respectively in 2010. These changes, together with such elite university schemes as Projects 985 and 2II, serve in turn to further hierarchize the Chinese system.

Starting from 2004, China's Ministry of Education (MoE), launched an initiative of cosponsoring a selected group of local universities with the provincial governments, particularly in those provinces without any national universities. The local universities selected in this scheme would enjoy similar status as the national universities affiliated to the MoE, with enhanced support (fundamentally in terms of resources and strategic planning) from the ministry. Up to now, there are 35 such local universities that have been "upgraded" to this seminational status. Some other central ministries (e.g., Ministry of Agriculture, Ministry of Industry and Information Technology, Ministry of Transport, Ministry of Culture, Ministry of Water Resources, etc.) have been following suit and gradually cosponsored some I०० universities and colleges with the provincial governments. Most of these universities and colleges were originally run by those central ministries, and later decentralized to local control. Now, they are somehow "recentralized." This move has put the aggregate size of national and seminational universities almost back to the level before decentralization.

\section{Behind the scene, it is no secret that over 30 percent of the graduates from low echelon institutions are now having difficulties finding jobs upon gradua- tion.}

Changes occurred at the lower/local levels, as well. Hundreds of newly founded local universities emerged amid expansion of enrollment. Initially, they emulated the veteran universities for their curricular and program offerings and played a major role of absorbing the increased enrollment, together with the fast-growing sectors of higher vocational colleges and private institutions. However, they soon experienced a difficult time. In order to ensure the public of quality of their curricular and program offerings, the MoE put these new universities under a periodic evaluation and assessment regime and essentially benchmarked them against the mature universities. This not only applies enormous pressure upon them but also places them in a hopeless competition, with the peers with a much-longer history. Even worse, such a competition quickly extended to their graduates in job market. Their graduates often lost from the peers at the older universities on institutional reputation and program quality and even to those from some higher vocational colleges and private institutions, on relevance of their program concentrations and learned skills. As a result, many of the new universities now seek to transform their curricular and program offerings and are keen to label themselves as Fachhochschule — universities of applied sciences. 
To facilitate such transformation, the MoE initiated a project in 2013 that aims to introduce the institutional fabric of European-originated applied type of universities to the Chinese system and supported the founding of a national alliance of such institutions. Given that the type of institution is new to higher education policymakers and practitioners in China, this alliance serves as a hub for drawing on the European experience and exploring their niches on Chinese soil. Its membership quickly grew to more than I50 local universities. This kind of "collective actions" was observed even earlier at the local level. For instance, in the province of Anhui, in central China, 16 universities (out of a total of 33 located in the province) formed a similar consortium in 2008 , helping one another with absorbing the ideas, experiences, and functions of the German Fachhochschule into their own operations. Now a consensus has been formed among these newly founded universities at the local level - that they need to follow a path alternative to conventional universities and focus on curricular and program offerings in applied areas. They see this path as the solution to addressing their deficiency in competitiveness in attracting students and preparing their employability.

\section{An Applied University Sector Emerging in China}

It appears that China is on the shift toward a binary higher education system that extends to the university level, from the current unitary and stratified one where all institutions are governed and measured according to one single set of criteria. While it is now premature, to state a binary system has already taken shape in Chinese higher education; and there is further evidence that supports such a speculation. The MoE stipulates that new universities are entitled to apply for offering advanced degree programs, after eight years of operating of undergraduate programs. Now, a few dozen of such universities are starting to offer master's degree programs - all with clear relevance to local needsand even professional doctoral programs. Lately, the MoE launched a pilot project, for a designated period from 2012 to 2017 , which allows new universities to offer master's and doctoral degree programs even before they fulfill the minimum years of operating undergraduate programs - as long as they can prove that their advanced degree programs are explicitly geared toward meeting the specific needs of the local, regional, and national development. Most recently, a MoE vice minister disclosed on March 22, 2014 that China would soon adopt dual track selection of university entrants, one for academic-focused universities, and the other for applied-type institutions. She further revealed that the MoE had prepared to convert around 600 local universities into those of applied sciences.

Thus, it is likely that Chinese higher education will have two parallel and discrete sectors. One will comprise the national, seminational, and those local universities that are included in Project 2II, as well as a few dozen traditional local universities. They are no more than 500 in total and provide a broad array of programs in the established disciplines and professions and increasingly in liberal arts and general education. They are academic and "cosmopolitan" in their outlook and, as such, support their academic staff to conduct intensive research and train the next generation of researchers. Less selective institutions will consist of the new universities, higher vocational colleges and private institutions. It is huge in size, incorporating close to 2,000 universities and colleges, which are local and teaching and service oriented. If they conduct any research, that exists as applied research. Limited upward mobility is now possible within the latter. A certain proportion of college graduates is allowed to continue to study in local universities, through participating in a competitive examination. With a shrinking age cohort in Chinese population, such mobility is expected to be enlarged and enhanced in the next decade. However, effective from 2008, all Projects 985 and 2II universities are not permitted to take college graduates through this articulation arrangement.

This shift helps diversify the interpretation of higher education quality and contributes to its relevance, while improving equity by providing alternative paths. This is of particular significance in a system like China's, which has a strong tradition of meritocracy and elitism in higher education that emphasizes a single dimension for assessing merit and tends to vertically divide all higher education institutions. On the other hand, it remains to be tested if the same tradition of meritocracy and elitism could ultimately drive changes back in the academic direction (i.e., academic drift). Nonetheless, however, from the early 1950 to the early I980s, when Chinese higher education was Sovietized, polytechnic universities were indeed granted high status in the system.

\section{Graduate Education in Malaysia and Thailand}

\section{Chiao-Ling Chien and David W. Chapman}

Chiao-Ling Chien is a researcher at the UNESCO Institute for Statistics, in Montreal, Canada. E-mail: cl.chien@unesco.org. David W. Chapman is Birkmaier Professor of Educational Leadership at the University of Minnesota. E-mail: chapmo26@umn.edu. The full report is available in the UNESCO Institute for Statistics Document Library: www. uis.unesco.org. 